\title{
Aleksander Posern-Zieliński: americanista, persona, maestro
}

\author{
Tarzycjusz Buliński y Mariusz Kairski
}

\begin{abstract}
Resumen
La presente reseña muestra las principales facetas en las cuales se ha desenvuelto el eminente investigador americanista Aleksander Posern-Zielinski, haciendo también un breve recorrido en torno a algunas etapas de su vida como son sus primeros años $y$ vida familiar, sus inicios como investigador, su paso a la investigación de campo, su época de becario internacional y doctorante, su inmersión en la docencia universitaria y finalizando con su cargo como director del Instituto de Etnología y Antropología de la Cultura de la Universidad Adam Mickiewicz de Poznan (Polonia).
\end{abstract}

Palabras clave: etnología polaca, americanística polaca, antropología.

Abstract

ALEKSANDER POSERN-ZIELIŃSKI: AMERICANIST, MAN, MASTER

This overview presents the main facets of the development of the eminent scholar of American studies, Aleksander Posern-Zieliński. It also takes a brief look at several stages of his life, including early years and family life, the beginnings as a researcher and introduction to fieldwork, the period of international scholarship and doctoral studentship, and finally, assumption of a university teaching position, culminating with his acceptance of the charge of director of the Institute of Ethnology and Cultural Anthropology at the University of Adam Mickiewicz in Poznan (Poland).

Key words: Polish ethnology, Polish American studies, anthropology.

En 2013, el Profesor Aleksander Posern-Zieliński celebró 40 años de dedicación a la investigación y su septuagésimo cumpleaños. Mediante la publicación del presente tomo, los americanistas polacos desean manifestar su agradecimiento y respeto al gran Profesor.

Tarzycjusz Buliński - Instituto de Arqueología y Etnología de la Universidad de Gdansk; correo-e: tarzycjusz.bulinski@ug.edu.pl, tarzycjusz.bulinski@gmail.com

Mariusz Kairski - Instituto de Arqueología y Etnología de la Universidad de Gdansk; correo-e: mariusz.kairski@gmail.com 
En este texto no vamos a contar los logros científicos del Profesor ni su extensa carrera profesional, ni los cargos que desempeñó. Lo hizo muy bien Zbigniew Jasiewicz en un trabajo conmemorativo (2013) editado por Ryszard Vorbrich i Anna Szymoszyn (2013). Solamente destacaremos que a finales de mayo de 2014 la bibliografía del Profesor constaba de 338 publicaciones, entre las que hay libros (seis), artículos, aportaciones a trabajos colectivos, glosarios, reseñas, entrevistas, resúmenes y traducciones. Sus logros en el campo de edición y tutoría de trabajos científicos son igual de impresionantes: coordinó la publicación de dos revistas (Estudios Latinoamericanos, Ethnologia Polona), de una serie editorial (Trabajos del Comité de Ciencias Etnológicas de la PAN [Academia de Ciencias Polaca]), editó 8 libros ( $y$ fue coeditor de otros dos), fue tutor de 12 tesis doctorales y de 128 (jsic!) tesinas de licenciatura.

Nuestra intención es mucho más modesta. Queremos mostrar la carrera del Profesor como investigador, desde nuestra perspectiva subjetiva e intentar aproximar su biografía a nuestros lectores. Contar lo que nos parece particularmente interesante en su personalidad y lo que nosotros distinguimos como los períodos más importantes de su carrera profesional. Ambos nos consideramos discípulos suyos, pertenecientes a dos siguientes generaciones de antropólogos americanistas polacos. El Profesor influyó en gran medida en nuestros currículos científicos y no dudamos en hablar de él de manera ya poco usada en estos días, pues lo consideramos nuestro maestro. Trabajando a su lado desde hace más de tres décadas hemos podido forjar nuestra propia opinión sobre su trabajo de investigación, Sus prácticamente titánicas actividades organizativas y sobre él mismo en la dimensión personal. Por eso estamos convencidos de que no será ningún abuso por nuestra parte compartir con nuestros lectores la imagen del camino que recorrió el Profesor para llegar al momento actual. Momento, en el que se había convertido en maestro para muchos.

\section{Unas palabras sobre sus primeros años y su familia}

El Profesor nació el 11 de enero de 1943 en Dąbrowa Górna (entonces Ober Dammer), cerca de Lubin en la región de Baja Silesia, en una familia con raíces en Wielkopolska y Cracovia. Su padre, Julian, veterano de la batalla de Verdun, agricultor de formación que fue primero administrador y finalmente propietario de una explotación agraria, provenía de una familia patriótica de Poznan. Su abuelo, que fue maestro de escuela en Łubów en los tiempos de ocupación prusiana, fue expulsado del trabajo por no subordinarse a los mandatos de las fuerzas ocupantes. Un tío paterno suyo participó en la guerra polaco-soviética entre los años 1919 y 1921 como oficial profesional del Ejército Polaco de la Segunda República. Otro tío suyo, que después de la Segunda Guerra Mundial fue canónigo en Mogilno, combatió en la Insurrección de Wielkopolska, fue prisionero en el Campo de concentración de Dachau y, después de la liberación del campo, capellán del ejército del general Maczek 
en el norte de Alemania. La madre del Profesor, Eleonora, de soltera Białecka de Blanchard, nació en una familia asentada en la región de Cracovia y Cieszyn. Su padre, ingeniero petrolero, desapareció en circunstancias desconocidas en 1905 cuando intentaba pasar de las entonces Indias Holandesas (la actual Indonesia), donde trabajaba en un contrato, hacia Japón, para luchar contra los rusos. Eleonora fue al colegio en Cracovia. Después de terminar el bachillerato y antes de la guerra, trabajó como funcionaria en el Consulado Polaco en Lipsk. El Profesor tiene dos hermanos: Witold, ingeniero mecánico que emigró a Alemania, y Janina. El hijo único del Profesor, Juliusz, es licenciado en física técnica por la Universidad Politécnica de Poznan en la especialidad de procesos tecnológicos de la industria alimentaria. La esposa del Profesor, Mirosława Kazimiera, de soltera Nowacka, es doctora en etnología, americanista, discípula de la profesora Maria Frankowska. Durante muchos años trabajó como investigadora en la Academia Polaca de Ciencias (Sección de Etnología). Después de abandonar el trabajo de investigación, trabajó hasta la jubilación como directora para el desarrollo de proyectos de investigación en la Federación de Ciudades Polacas.

El Profesor llegó con su familia a Poznan después de la Segunda Guerra Mundial, en 1947. Se instalaron en el barrio de Wilda. Desde el punto de vista de modelos culturales, la casa donde se crió el Profesor fue el resultado de la conjunción de diferentes tradiciones (de Galitzia, de Varsovia, de donde era su abuela y de Wielkopolska). Su calle y los compañeros del patio de la casa le enseñaron las costumbres y el dialecto de Poznan y la visión del mundo típica para el lugar. Empezó la escuela primaria ( $n^{\circ} 42$, en la calle Różana) con 6 años. Vista desde la perspectiva de hoy, su clase resultó bastante excepcional, a pesar de que la componían los niños de la vecindad. Muchos de los compañeros de pupitre del Profesor estudiaron carreras universitarias, tres llegaron a profesores universitarios (de los cuales dos fueron etnólogos), uno, J. Strzałko, fue vicerrector de la Universidad Adam Mickiewicz (UAM). Otro amigo del Profesor, Wojciech Wróż (doctor en física de la Academia Polaca de Ciencias) era un conocido himalayista y murió en el descenso del K2. Los lazos de amistad de aquellos tiempos se mantienen vivos hasta hoy. En el colegio, el Profesor no fue (como él mismo admite) un alumno particularmente aplicado, porque dedicaba mucho tiempo a juegos bastante peligrosos en las ruinas de fortificaciones, viejos cementerios destruidos durante la guerra o en los prados a orillas del río Warta. En esos tiempos descubrió el encanto de la lectura y se convirtió en un «devorador» de libros, sobre todo de divulgación, sobre temas históricos, arqueológicos y la historia de las religiones. Obligado a pasar mucho tiempo en casa por las enfermedades, aprovechó para leer muchísimo. Cuando terminó la escuela primaria, en 1956, ingresó en el Liceo ${ }^{\circ} 6$ Ignacy Paderewski, donde estudió en un grupo bilingüe polaco-alemán. En esta etapa de su formación, sus calificaciones mejoraron bastante, lo que le permitió obtener una pequeña beca del liceo, que significó una importante ayuda económica para su madre (entonces ya viuda y con un modesto 
trabajo de funcionaria). Obtenía las mejores notas de geografía, historia y ifísica! El profesor de esta asignatura llegó a aconsejarle que estudiara la carrera de física en la universidad. En realidad, al Profesor le interesaban cosas bien distintas, como por ejemplo la mitología de los pueblos eslavos, baltos, germanos y romanos, la procedencia y el desarrollo de las creencias religiosas, los orígenes de la cultura humana, las civilizaciones antiguas y también la historia de los incas, aztecas y otros pueblos indígenas del Nuevo Mundo. Estos intereses hicieron que, después de consultarlo, entre otros, con el doctor W. Armon y la profesora Maria Frankowska, en 1960, después de aprobar el examen de bachillerato, decidió estudiar etnografía. Dudó un poco entre la arqueología y la etnografía, pero finalmente prevaleció la perspectiva de ocuparse de algo más "palpable» y real, como la etnografía. En aquel tiempo no fue fácil entrar en esta facultad (reactivada apenas unos años antes), ya que cada año eran admitidas solamente 7 personas, presentándose al examen de ingreso unos 8 candidatos por cada plaza. En el examen de ingreso tuvo que contestar preguntas que, curiosamente, más adelante se convirtieron en los principales ejes de su carrera profesional («características culturales y geográficas de la América del Sur», «interrelaciones entre culturas y civilizaciones" y "consecuencias de dichos procesos»). En el jurado estaba la profesora Maria Frankowska, quien más adelante fue la mentora del Profesor. Y así comenzó la carrera profesional del Profesor.

\section{Investigador}

La primera etapa de la carrera del Profesor estuvo dedicada al tema que centró sus intereses de investigador en aquellos años. Hoy, cuando es el más eminente de los americanistas polacos, no todos recordarán que lo que le fascinaba en aquellos tiempos era Oceanía. Un área de investigación muy poco agradecida en la situación socio-política de nuestro país en aquel momento (estamos hablando de los años de la década de 1960, cuando la etnografía polaca estaba prácticamente totalmente aislada de la etnología mundial). Fue entonces, cuando el Profesor se dio a conocer por primera vez como Investigador con la «I» mayúscula. Encontró y consiguió traer a Polonia toda la literatura mundial sobre la cultura de Oceanía, cosa muy difícil en aquel momento. El Profesor no se rendía ante los obstáculos. No aceptaba las llamadas «dificultades objetivas». Sus principios de honestidad científica están muy bien reflejados en las siguientes palabras suyas: «cuando hablo de algún tema, tengo la obligación absoluta de obtener todos los conocimientos sobre esta materia y tener la certeza de saber de qué estoy hablando». Hasta hoy nos impresiona su primer libro, escrito sobre la base de su tesina de licenciatura, elaborada tras el estudio de toda la literatura dedicada a Oceanía de aquel período. Ahora ni siquiera somos capaces de imaginar cuánto trabajo le costó aquello, cuánta perseverancia y sobre todo, cuánta fe en que merecía la pena hacerlo de esta manera. Los efectos de su trabajo fueron impresionantes. Querido lector, si no lo conoces todavía, 
busca este libro grueso, de edición modesta que hasta hoy sirve de referencia a los estudiantes que tienen interés en saber cómo debe ser una disertación creativa. En la era de Internet y de fácil acceso a los trabajos de investigación científica, que trae en consecuencia más bien la superficialidad que la profundidad (ya en los años de la década de 1950 Stanisław Lem escribió que el exceso de información bloquea de forma eficaz el pensamiento crítico), las aptitudes así son cada vez menos frecuentes. Este afán de hacerlo todo lo mejor que uno sea capaz, independientemente del grado de dificultad, es, en nuestra opinión, una de las primeras cosas por las cuales nuestro Homenajeado llegó a ser el maestro de muchos de nosotros.

Este rasgo se hace notar en otros trabajos del Profesor de aquella época. Para nosotros son particularmente impresionantes tres de sus trabajos de investigación, separados tanto en el tiempo como por su significado social y profesional. El primero de ellos es la edición científica del libro de Joan Metge titulado The Maoris of New Zealand (1971). Este libro, relativamente breve, se concentra sobre todo en la situación contemporánea de los indígenas del archipiélago y habla muy poco de la historia de los maoríes y de su antigua cultura. Pero en aquel tiempo fue la primera publicación científica sobre los maoríes en lengua polaca. ¿¿Y qué fue lo que hizo el entonces licenciado Posern-Zieliński? Escribió una introducción en la que resumió todos los conocimientos etnológicos e históricos sobre los maoríes de aquel momento, redactó las notas explicativas y un glosario y escogió las ilustraciones. En nuestra opinión dicha introducción es por lo menos igual de interesante que el mismo libro y después de leerla, puede no ser necesario leerlo (si lo que uno busca es conocer la historia de los maoríes). Observamos esa misma honestidad y entusiasmo en otras ediciones científicas suyas, como por ejemplo Los Vikingos del Pacífico de P.H. Buck.

El segundo trabajo de investigación importante del Profesor fue su tesis doctoral. $\mathrm{Y}$ es precisamente esta disertación sobre los Movimientos sociales y religiosos de los indios de la América Hispana (s. XVI-XX), y no su versión reducida publicada en forma de libro en 1974, una obra impresionante en todos los aspectos, que todavía hoy, pasados tantos años, destila la claridad del pensamiento, la enorme disciplina a la hora de separar la descripción de la interpretación y el esfuerzo benedictino de buscar y documentar todos los detalles. Es una pena que por razones de edición, el libro no incluya la parte de la tesis dedicada a los movimientos que tuvieron lugar en la Amazonia, una región muy interesante y muy poco conocida por los investigadores en aquel momento.

La tercera obra de investigación que constituye un trabajo modélico para nosotros, es un libro escrito por el Profesor conjuntamente con su esposa, titulado Creencias y rituales de los indios (1979). El trabajo quita el aliento por su ímpetu y alcance. Aparentemente es un libro de divulgación, pero contiene una extensa y ambiciosa introducción analítico-crítica y una inmensa y bien seleccionada bibliografía. De manera muy clara el libro describe, explica las funciones y permite comprender 
las creencias de los indios y los rituales que las acompañan. Todo ello se presenta al lector, que no es especialista en la materia pero es exigente, de manera profunda y nada banal, sin simplificaciones y de forma sistemática. El objetivo del libro es dar la visión de la totalidad (destacamos que se trata de presentar el fenómeno en todo el Nuevo Mundo, es decir en dos grandes continentes). Hasta hoy Creencias y rituales de los indios es una de las lecturas fundamentales para los estudiantes de todas las facultades de etnología en Polonia.

En nuestra opinión, estos tres ejemplos dan buena fe de la excelencia del método de investigación científica del Profesor. Creemos que nunca dejó de trabajar de esta manera y hasta hoy nunca se permite «atajos» en sus trabajos.

\section{Investigador de campo}

La segunda etapa comienza con las expediciones del Profesor. Fue uno de los iniciadores y primeros participantes de las expediciones polacas a los Andes y contribuyó a la creación del modelo polaco de investigación americanista interdisciplinario. Su forma de realizar los trabajos de investigación etnológica de campo sirvió como modelo a otros eminentes americanistas polacos de las décadas de 1970, 1980 y 1990 y también a arqueólogos, etnoarqueólogos, etnohistoriadores, etnógrafos, antropólogos de la cultura o musicólogos. Estos hechos son conocidos por todos. No obstante, desde nuestra perspectiva, lo más importante es que en ese período el profesor descubrió en sí mismo el instinto de investigador de campo. Resultó obvio que el contacto con otras personas es algo muy importante y de vital transcendencia, que además produce excelentes resultados para la investigación. Esta disposición a trabajar en el campo y la pasión por este tipo de trabajo, acompañan al Profesor hasta hoy. En ningún período de su vida dejó de realizar estudios de campo (primero en equipos, más tarde de forma individual). Cabe destacar que el "abandono" del trabajo de campo en las fases más maduras de la carrera de investigador es un fenómeno frecuente entre los antropólogos. Porque la investigación de campo no es fácil. Muchas veces cansa y confunde, con el tiempo conduce a la rutina y a la falta de empatía. Desde la perspectiva de nuestras propias experiencias de campo, nos resultan muy cercanas las divertidas anécdotas del Profesor que cuenta como en algún lugar fue tomado por cura y cómo la autoridad del cura y la autoridad del profesor-investigador le proporcionaban poder y sensación de seguridad, pero dificultaban la proximidad e inmediatez en las relaciones con la gente.

En nuestra opinión, es el segundo elemento determinante de la personalidad del maestro. Gracias a su actitud empírica y a sus experiencias, el Profesor consiguió y sigue manteniendo el equilibrio necesario entre la teoría y los hechos reales. Ninguna concepción presentada en sus trabajos o conferencias estaba desprovista de referencias a la realidad etnográfica. En nuestra opinión, es la mejor manera de practicar la antropología. 


\section{El investigador de etnicidad y de cultura}

La tercera etapa importante en la carrera profesional del Profesor corresponde al período en el que no realizó grandes expediciones de campo ni programas de investigación de gran alcance en el espacio y en el tiempo. Hablamos de la época de estudios en el extranjero con becas internacionales (incluida la beca de la Fundación Fulbright y la de la fundación Kościuszko) y de intenso trabajo para finalizar la tesis de doctorado superior (1982). Este período parece menos espectacular, pero solo aparentemente. Nosotros pensamos que es el momento más importante en la carrera del Profesor. Durante las múltiples estancias, reuniones, conferencias y debates en el extranjero, el Profesor entró en contacto con la etnología mundial, además, de la mejor manera posible, es decir conociendo personalmente a los investigadores de todo el mundo. Al mismo tiempo, creó sus propios enfoques de los problemas, las soluciones de autor y los análisis críticos de conceptos y estudios empíricos de otros. En realidad, fue entonces cuando se formaron los fundamentos teóricos y la extraordinaria capacidad de síntesis del Profesor, que dieron sus frutos en las tres décadas siguientes. Consideramos que sin los estudios sobre los inmigrantes polacos en América y sin la percepción creativa de los conceptos de antropología mundial en el campo de la etnicidad, no hubieran sido posibles los posteriores trabajos del Profesor sobre la situación actual de los indios en las sociedades multiculturales de la América del Sur, ni los ampliamente entendidos estudios étnicos, políticos e interdisciplinares. Y, seguramente, no hubieran aparecido los trabajos de síntesis y manuales, como Etnicidad (2005) o los fantásticos resúmenes de los debates sobre la concepción de aculturación (Interpretación etnológica de los procesos de aculturación, 1993) o de aculturación y asimilación (Aculturación y asimilación - dos aspectos del proceso de cambio étnico desde el punto de vista antropológico y etnohistórico, 1999). Cualquier investigador sabe que lo más difícil de escribir en el campo científico es la síntesis y el manual. Estamos convencidos de que en este período el Profesor progresó un paso más en su carrera y al rigor científico y a la pasión por el trabajo de campo añadió la capacidad de síntesis y la destreza del pensamiento teórico.

\section{Docente e inspirador}

La cuarta etapa de la carrera del Profesor está relacionada con la docencia universitaria y conferencias, que dando cuenta de sus propias búsquedas y fascinaciones sirvieron de inspiración para otros. Los dos recordamos muy bien las clases del Profesor y lo que sentimos en aquellos momentos, pero es hoy, cuando nosotros mismos tenemos ya una dilatada experiencia docente, cuando somos capaces de comprender en que consiste la fuerza de las conferencias del Profesor. Éstas se caracterizan por dos cosas. La primera, es la extraordinaria capacidad de síntesis. No recordamos ningún tema que el Profesor no fuera capaz de sintetizar. Sabe pre- 
sentar cualquier fenómeno, cualquier secuencia de acontecimientos, concepción o tipología a su manera y de forma clara, comprensible y abarcable para el oyente. Hasta el día de hoy seguimos envidiando al Profesor su capacidad de trazar fronteras y detectar las características más relevantes de cualquier fenómeno o problema y de ordenarlos en una tipología aparentemente sencilla. Otra de las capacidades del Profesor es la facilidad con la que es capaz de explicar los fenómenos más complejos valiéndose de ejemplos sencillos y comprensibles, casi siempre tomados de sus estudios de campo, y la destreza en pasar en un instante del nivel abstracto de síntesis a un ejemplo palpable. Gracias a ello, recordamos sus conferencias sobre todo por las imágenes que fue capaz de generar en nuestras mentes. No hace falta que añadamos que estas clases o consultas fueron para muchos, no solamente para nosotros, extraordinariamente inspiradoras. Sería difícil contar todos los casos de personas que nos relataron que su interés por la antropología viene de una inspiradora conferencia de Posern-Zieliński. Ahora, cuando vemos nuestras experiencias de las clases con el Profesor desde cierta distancia, nos parece que el Profesor tiene un don especial: los que participan en sus clases, consultas y seminarios tienen la sensación de estar en contacto vivo y no convencional con la ciencia. Con el conocimiento profundo del tema y con la capacidad de juicio crítico, tanto sobre el objeto de la conversación, como sobre sus propias opiniones. De esta manera se forma la autoridad.

\section{Director del Instituto}

Y finalmente, la quinta etapa, relacionada con la dirección de un gran centro de investigación y enseñanza, es decir el Instituto de Etnología y Antropología de la Cultura de la UAM de Poznan. El Profesor lo dirigió, o mejor dicho, organizó su actividad de investigación y docente durante 12 años. En nuestra opinión, esta fue una etapa excepcional en la historia del Instituto. En este tiempo, el Instituto se convirtió en uno de los centros antropológicos de referencia en nuestro país. Estamos convencidos de que este éxito se debe al Profesor. Antiguamente, el Instituto estaba compuesto por varias decenas de profesores y doctores que se dedicaban cada uno a su especialidad. Más que un equipo, era un conjunto de personas con diversos intereses y caracteres. Sin embargo, el Profesor supo crear un marco a este conjunto y dirigir las actividades individuales de tal manera que sus efectos sobresalían por encima de los proyectos unitarios y empezaron a convertir el Instituto en un coherente, si bien muy amplio, proyecto etnológico. El Profesor supo convencer a todos, incluidos a nosotros dos, sobre la bondad de las soluciones que se inscribían en su visión del centro de investigación (en el sentido de investigación científica del que hablamos antes) con dos fuertes ramas: la etnológica, dirigida hacia los estudios etnológicos en Polonia y fuera de sus fronteras, y la antropológica, dirigida hacia la reflexión teórica y la perspectiva interpretativa. Precisamente, esta capaci- 
dad de mediación y negociación de las soluciones, la huida de las limitaciones de voluntades y pasiones de las personas y de las medidas estandarizadas de gestión y poder, hacen del Profesor una persona fuera de lo común. Este afán y habilidad de convencer en las situaciones en las que existe la posibilidad de imponer la solución por aplicación de la autoridad jerárquica, despiertan en nosotros un gran respeto para la persona del Profesor y nos parecen un modelo a seguir. Sobre todo ahora, cuando nosotros mismos nos enfrentamos a los retos de creación de un nuevo centro de investigación etnológica en Gdańsk. En esos momentos nos sirve de referencia la forma en que el Profesor no solamente creó el espacio para la investigación, sino también para una vida agradable en su Instituto.

A la luz de lo constatado arriba, podemos decir que el homenajeado no solamente es un digno continuador y el más eminente de los discípulos de la profesora Maria Frankowska. En nuestra unánime percepción, es un ejemplo del mejor discípulo que uno puede imaginar, es decir del discípulo que superó a su maestro. Gracias a él, la americanística polaca, sobre todo en el campo de la etnología, se dio a conocer en el amplio océano de la investigación científica mundial, y junto con la arqueología y la etnohistoria se ganó el reconocimiento en todo el mundo. ¡Enhorabuena Profesor! 
Original title / titulo original: Aleksander Posern-Zieliński: americanista, persona, maestro

\section{Author(s)/ autor(es):}

\section{Tarzycjusz Buliński, Mariusz Kairski}

Published originally as/ Publicado originalmente en:

Estudios Latinoamericanos, 33/34 (2013-2014), pp. 11-19

DOI: https://doi.org/10.36447/Estudios2014.v33-34.art1

Estudios Latinoamericanos is a journal published by Polish Society for Latin American Studies (Polskie Towarzystwo Studiów Latynoamerykanistycznych).

Polish Society for Latin American Studies is scholarly organization established to facilitate research on Latin America and to encourage and promote scientific and cultural cooperation between Poland and Latin America.

Estudios Latinoamericanos, revista publicada por la Sociedad Polaca de Estudios Latinoamericanos (Polskie Towarzystwo Studiów Latynoamerykanistycznych).

Sociedad Polaca de Estudios Latinoamericanos es una asociación científica fundada con el fin de desarrollar investigaciones científicas sobre América Latina y participar en la cooperación científica y cultural entre las sociedades de Polonia y América Latina. 